Supporting Information

\title{
Bioinspired Noniridescent Structural Color with Hidden Patterns for AntiCounterfeiting
}

Panmiao Liu ${ }^{\dagger}$ Wenya Chang, Lingsha Ju, ${ }^{\dagger}$ Lanling Chu, ${ }^{\S}$ Zhuoying Xie, ${ }^{*}{ }^{\ddagger}$ Jialun $\mathrm{Chen}^{\ddagger}$ and Jianjun Yang ${ }^{*+}$

'Department of Anesthesiology, The First Affiliated Hospital of Zhengzhou University, Zhengzhou, China, 450052

State Key Laboratory of Bioelectronics, School of Biological Science and Medical Engineering, Southeast University, Nanjing, China, 210096

${ }^{\S}$ Faculty of Food Science and Engineering, School of Light Industry and Food Engineering, Nanjing Forestry University, Jiangsu Province, Nanjing, China, 210037

'Department of Pharmaceutical Engineering, School of Engineering, China Pharmaceutical University, Nanjing, China, 210009

* Corresponding author: zyxie@ seu.edu.cn; jianjunyang1971@163.com 
a

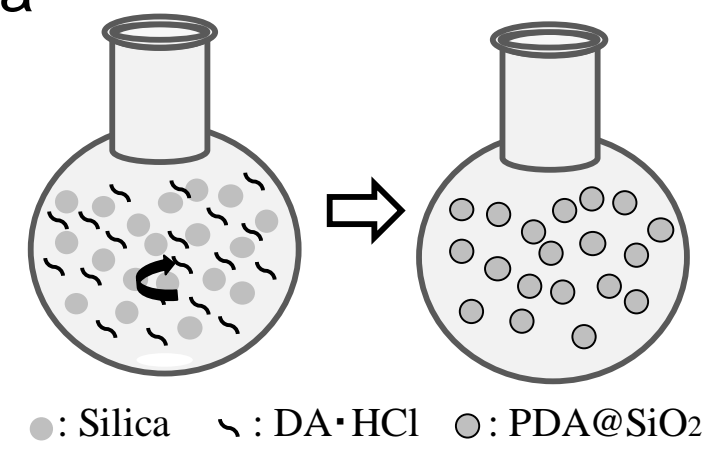

C

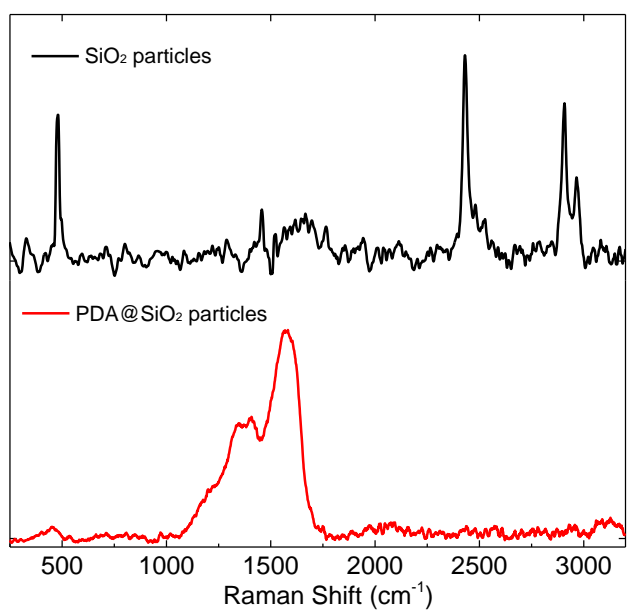

b

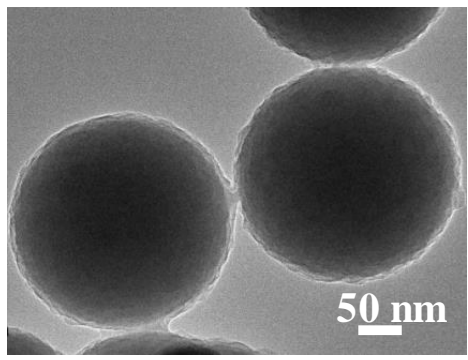

d

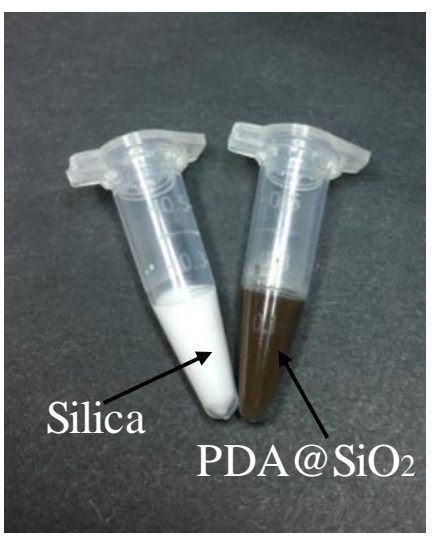

Figure S1 (a) Diagram of synthesis of PDA@ $\mathrm{SiO}_{2}$ particles. (b) TEM image of $\mathrm{PDA} @ \mathrm{SiO}_{2}$ particles. (c) Raman spectras of $\mathrm{SiO}_{2}$ particles and PDA@ $\mathrm{SiO}_{2}$. The characteristic bands of $\mathrm{SiO}_{2}$ particles are in the range of 500 and $2490 \mathrm{~cm}^{-1}$. While PDA@ $\mathrm{SiO}_{2}$ samples spectra appeared two strong bands at 1355 and $1579 \mathrm{~cm}^{-1}$, which can be assigned to the deformation of the catechol group in the PDA structure. (d) Photograph of PDA@ $\mathrm{SiO}_{2}$ and $\mathrm{SiO}_{2}$ suspension. 

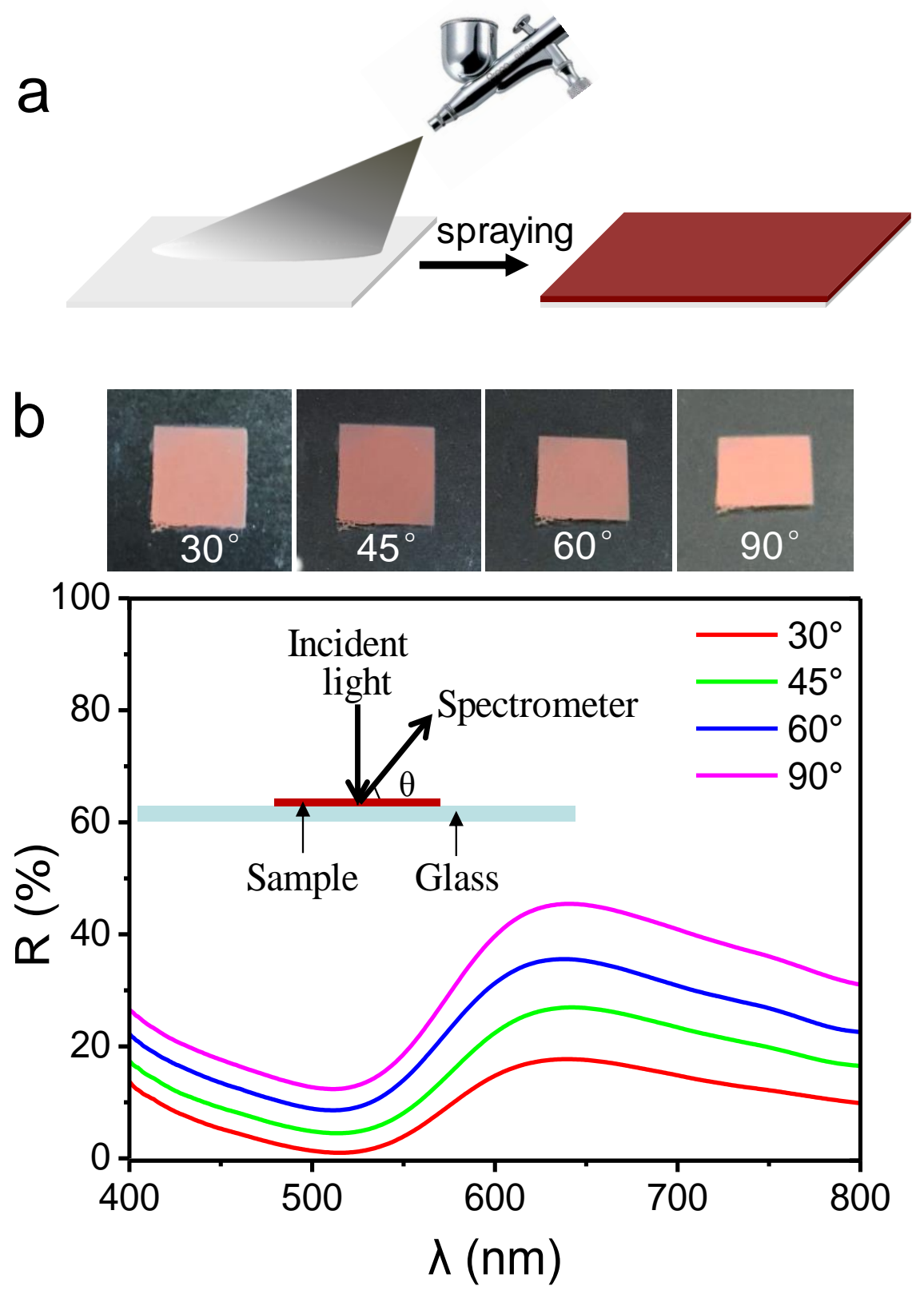

Figure S2 (a) Diagram of fabrication of amorphous $\mathrm{PDA} @ \mathrm{SiO}_{2}$ arrays. (b) Photographs and reflection of arrays at various viewing angles fabricated by $295 \mathrm{~nm}$ $\mathrm{PDA} @ \mathrm{SiO}_{2}$. The insert image Diagram of reflection detection of PDA@ $\mathrm{SiO}_{2}$ arrays. 

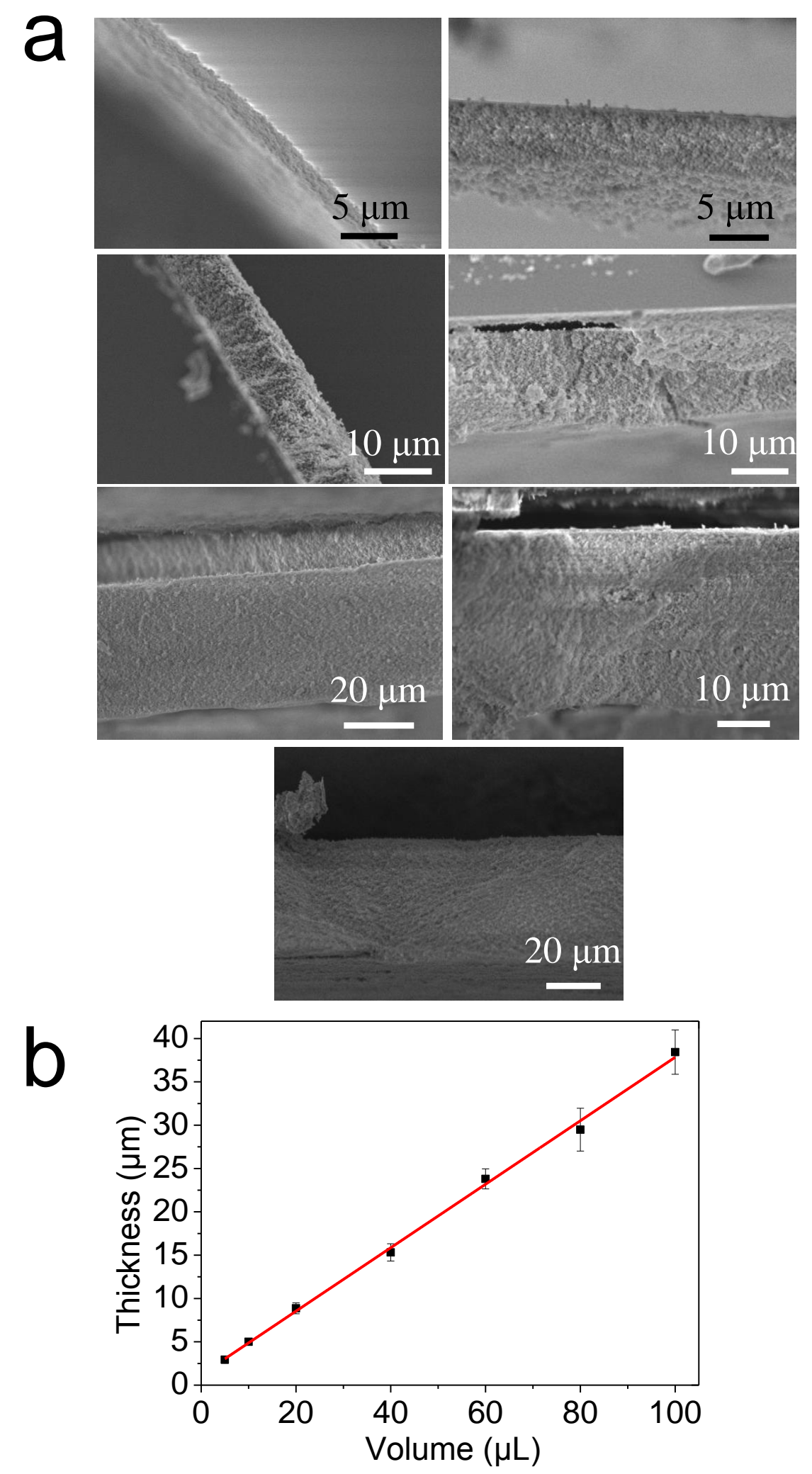

Figure S3 (a) SEM images of cross-section of PDA@ $\mathrm{SiO}_{2}$ arrays with $3 \mu \mathrm{m}, 5 \mu \mathrm{m}, 9$ $\mu \mathrm{m}, 16 \mu \mathrm{m}, 23 \mu \mathrm{m}, 31 \mu \mathrm{m}, 40 \mu \mathrm{m}$. (b) The relationship between the thickness and volume of the dispersions containing $295 \mathrm{~nm}$ sized $\mathrm{PDA} @ \mathrm{SiO}_{2}$ particles at a concentration of $0.07 \mathrm{~g} / \mathrm{ml}$.

S4. Color theory and calculation of three tristimulus values 
Color is a perception of the human eye vision system to light. The CIE 1931 color spaces were firstly defined quantitative links between physical pure colors in the electromagnetic visible spectrum, and physiological perceived colors in human color vision. The mathematical relationships are essential tools for color management. For colored measurement, electromagnetic visible spectrum was defaulted to absolute reflection spectra, obtained with the calibration standard whiteboard as completely diffuse reflector. Absolute reflectance is a bridge of the visual color to the colored data, so-called tristimulus values (CIE XYZ), calculated by the CIE's color matching functions. Tristimulus values (CIE XYZ) are the three parameters that correspond to the levels of stimulus of three types of cone cells in the retina of the human eyes to the light of certain wavelengths in the visible region, which peaks at approximately 430 $\mathrm{nm}, 540 \mathrm{~nm}$, and $570 \mathrm{~nm}$. The CIE XYZ color space is deliberately designed that the $\mathrm{Y}$ parameter is a measure of the luminance of a color. The chromaticity of a color is then specified by the two derived parameters $\mathrm{x}$ and $\mathrm{y}$, two of the three normalized values being functions of all three tristimulus values $\mathrm{X}, \mathrm{Y}$, and $\mathrm{Z}$. The derived color space specified by $x, y$, and $Y$ is known as the CIE xyY color space and is widely used to specify colors in practice.

All color sensations are in principle endowed with inherent tristimulus values (CIE $\mathrm{XYZ}$ ), which could be used for the evaluation of three attributes of color: hue, luminance and saturation. Among them, hue presents the appearance of a color and is represented by the dominant wavelength in the CIE xyY color space. Dominant wavelength is wavelength of spectral trajectory sited on the intersection point of chromaticity parameter $(\mathrm{x}, \mathrm{y})$ of this color with the spectral trajectory. Luminance of a color specifies the lightness of the color. In the CIE xyY color space, $\mathrm{Y}$ parameter is a measure of this attribute. Saturation denotes the purity of a color. In the CIE xyY color space, the quantitative value to specify this property is calculated as follows:

$$
S=\frac{X_{\lambda}+Y_{\lambda}+Z_{\lambda}}{X+Y+Z}
$$

In the formula, $\mathrm{X}, \mathrm{Y}$ and $\mathrm{Z}$ are the three tristimulus values of this color and $\mathrm{X}_{\lambda}, \mathrm{Y}_{\lambda}$ and $Z_{\lambda}$ are the tristimulus values of the corresponding dominant wavelength sited in the spectral trajectory. 


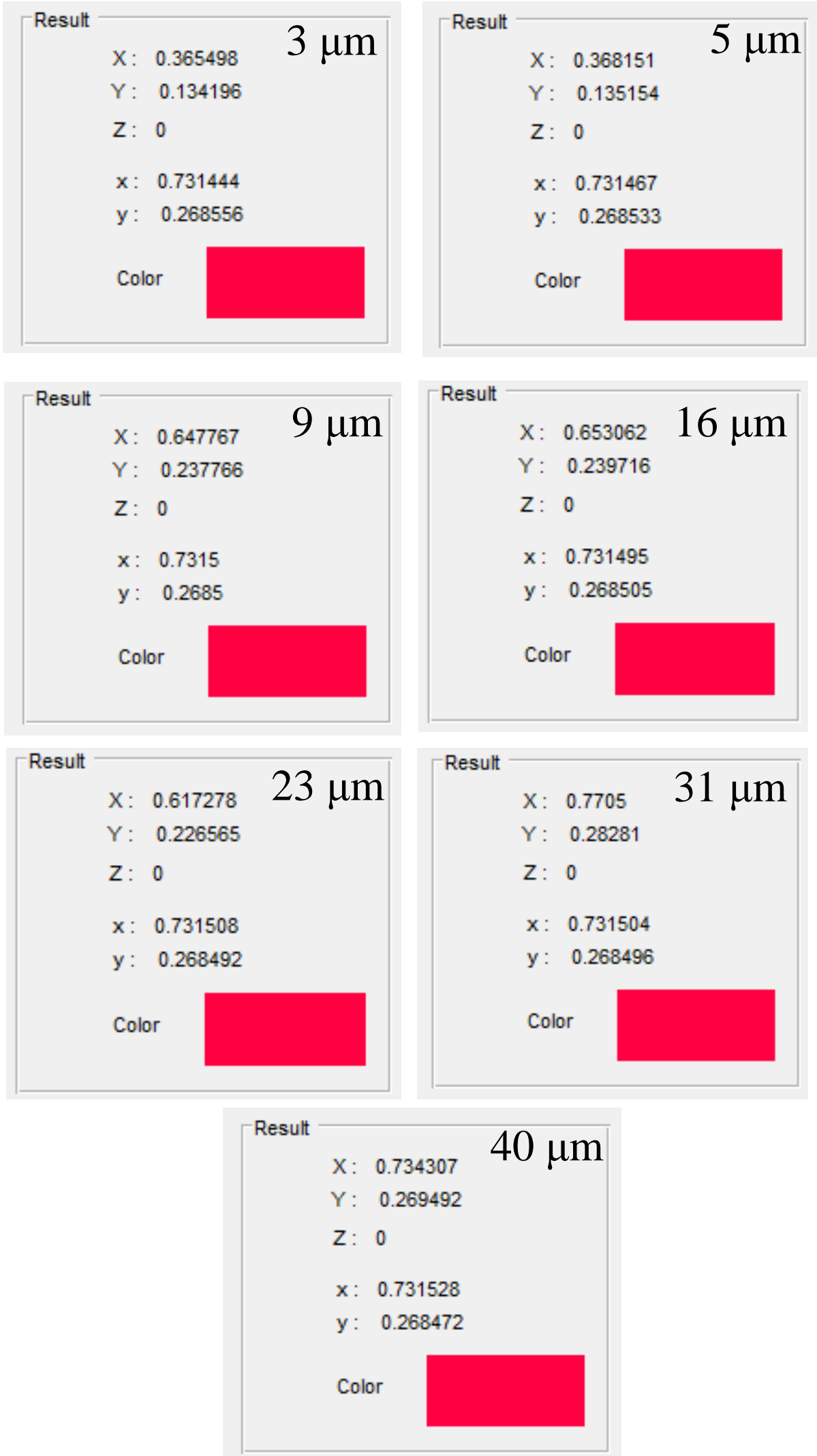

Figure S4 The results of the three tristimulus values and coordinate values of PDA@ $\mathrm{SiO}_{2}$ structural colors with different thickness caculated by a CIE co-ordinate caculator software. 

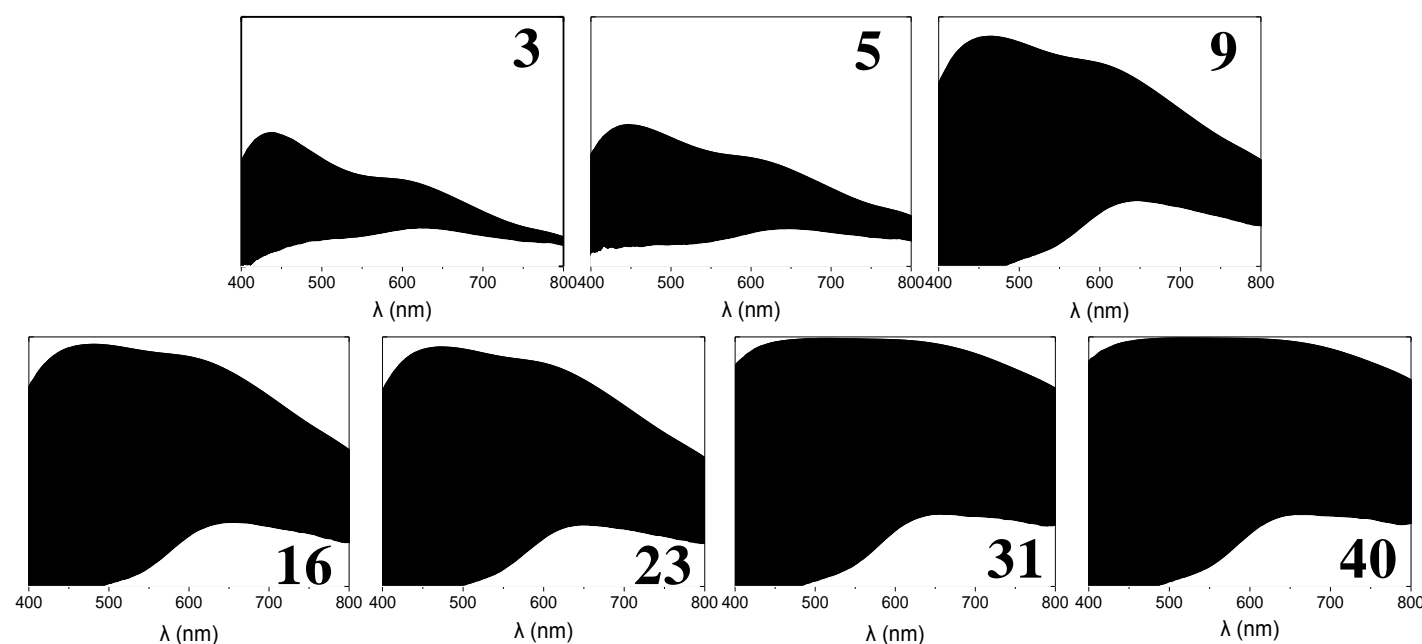

Figure S5 The absorption integral area of PDA@ $\mathrm{SiO}_{2}$ structurally colored arrays with different thicknesses $(\mu \mathrm{m})$ in air. 


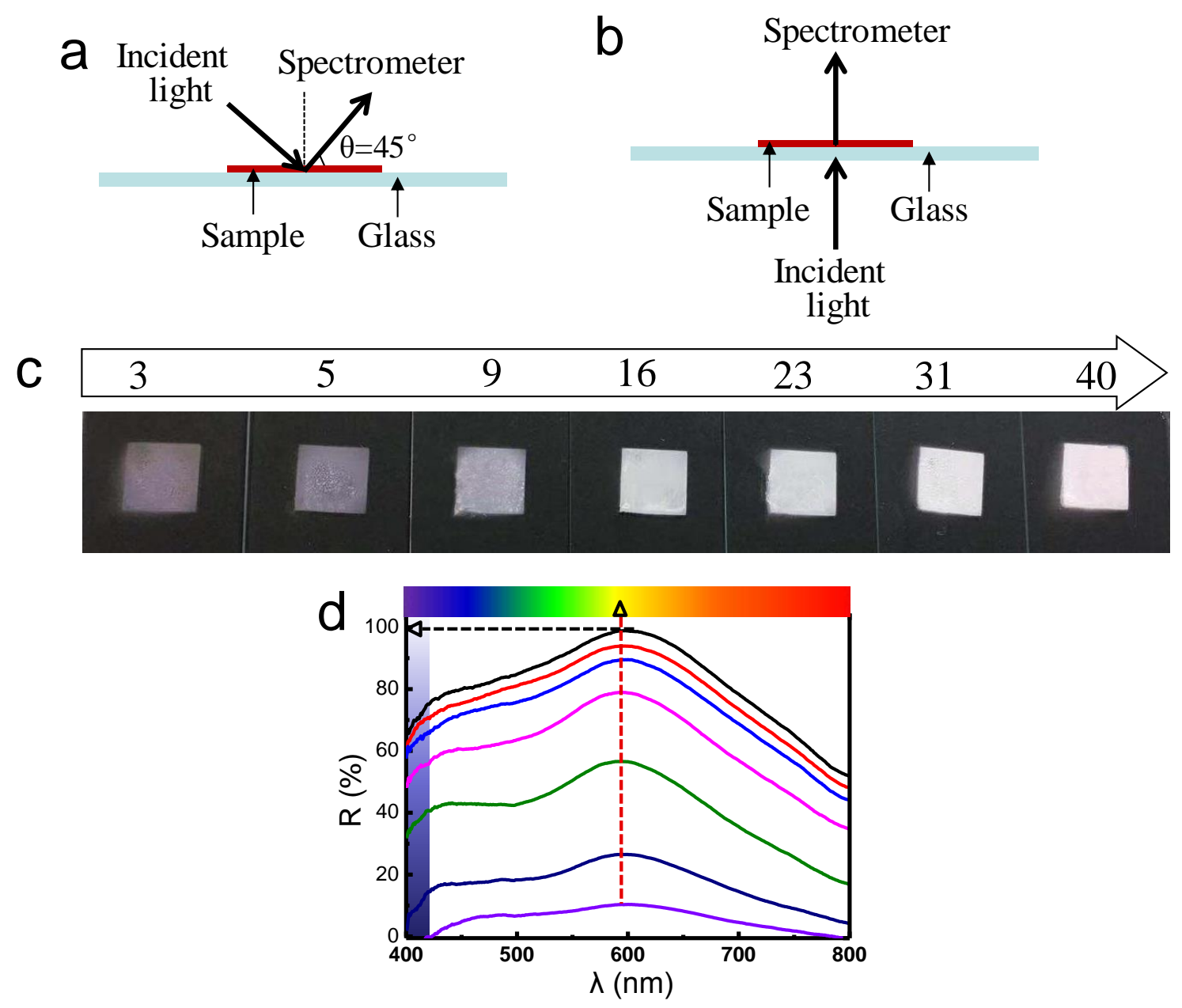

Figure S6 (a) Photographs of the PDA@ $\mathrm{SiO}_{2}$ structurally colored arrays fabricated by $\mathrm{SiO}_{2}$ particles with thicknesses of $3 \mu \mathrm{m}$ (black line), $5 \mu \mathrm{m}$ (red line), $9 \mu \mathrm{m}$ (blue line), $16 \mu \mathrm{m}$ (pink line), $23 \mu \mathrm{m}$ (green line), $31 \mu \mathrm{m}$ (dark blue line), $40 \mu \mathrm{m}$ (purple line). (b) Reflection spectra of $\mathrm{SiO}_{2}$ arrays before water wetting. (c) Reflection spectra of $\mathrm{SiO}_{2}$ arrays after water wetting. (d) Reflection spectrum of structurally colored arrays fabricated by $\mathrm{SiO}_{2}$ particles with thicknesses of $3 \mu \mathrm{m}, 5 \mu \mathrm{m}, 9 \mu \mathrm{m}, 16 \mu \mathrm{m}, 23 \mu \mathrm{m}, 31$ $\mu \mathrm{m}, 40 \mu \mathrm{m}$ (from bottom to top) in the air. 


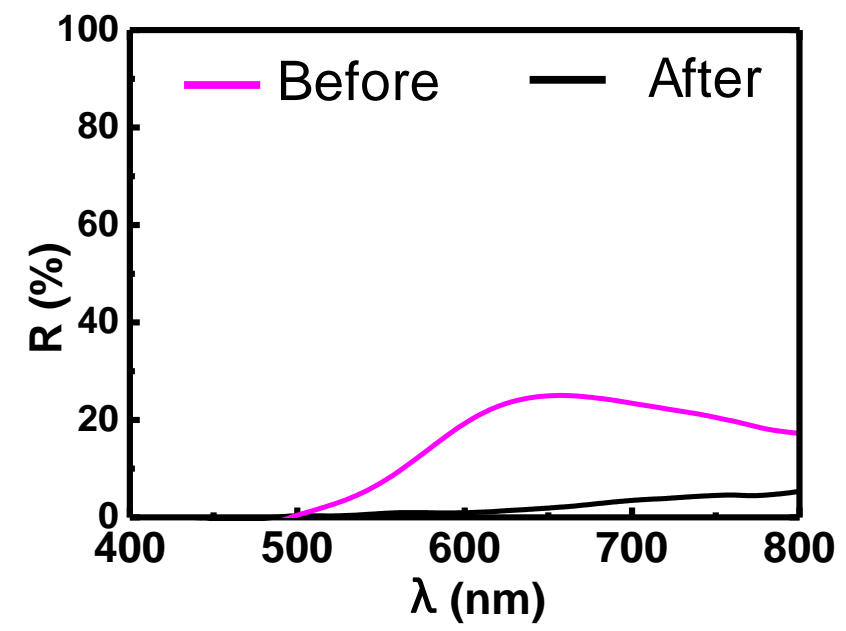

Figure $\mathrm{S} 7$ The reflection spectrum of $\mathrm{PDA} @ \mathrm{SiO}_{2}$ arrays of $16 \mu \mathrm{m}$ thickness before (pink line) and after (black line) water wetting.
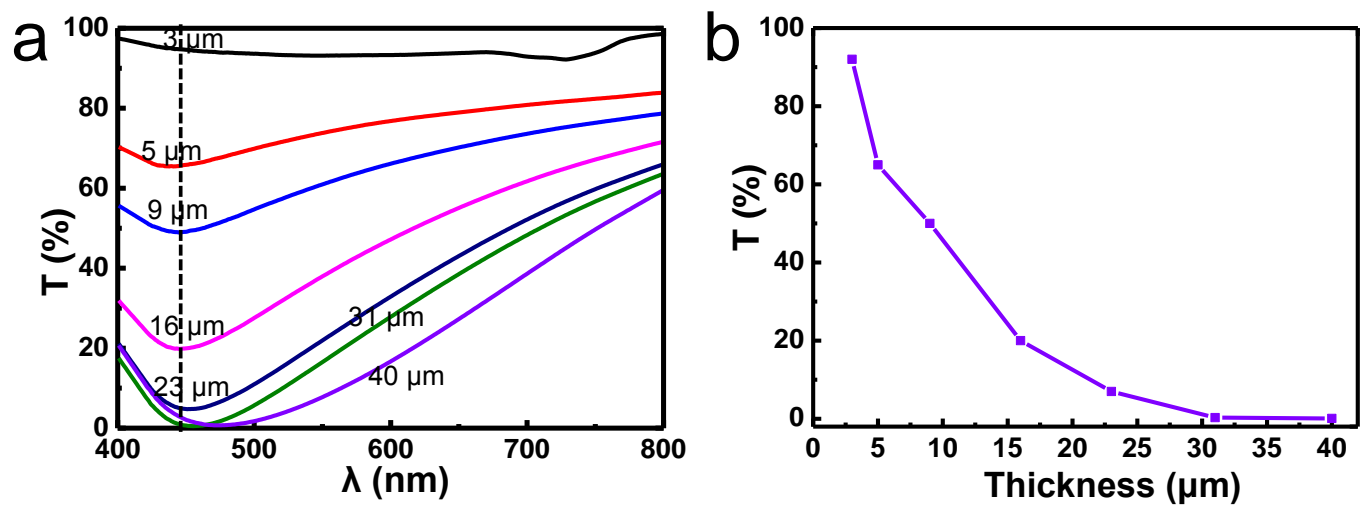

Figure S8 (a) Transmission spectrum of structurally colored arrays fabricated by 295 nm PDA@ $\mathrm{SiO}_{2}$ particles with thicknesses of $3 \mu \mathrm{m}, 5 \mu \mathrm{m}, 9 \mu \mathrm{m}, 16 \mu \mathrm{m}, 23 \mu \mathrm{m}, 31 \mu \mathrm{m}$, $40 \mu \mathrm{m}$ in the water. (b) The correlation curves of transmission ratio and thicknesses of $\mathrm{PDA} @ \mathrm{SiO}_{2}$ structurally colored arrays in the water at $450 \mathrm{~nm}$ of reflection wavelength. 


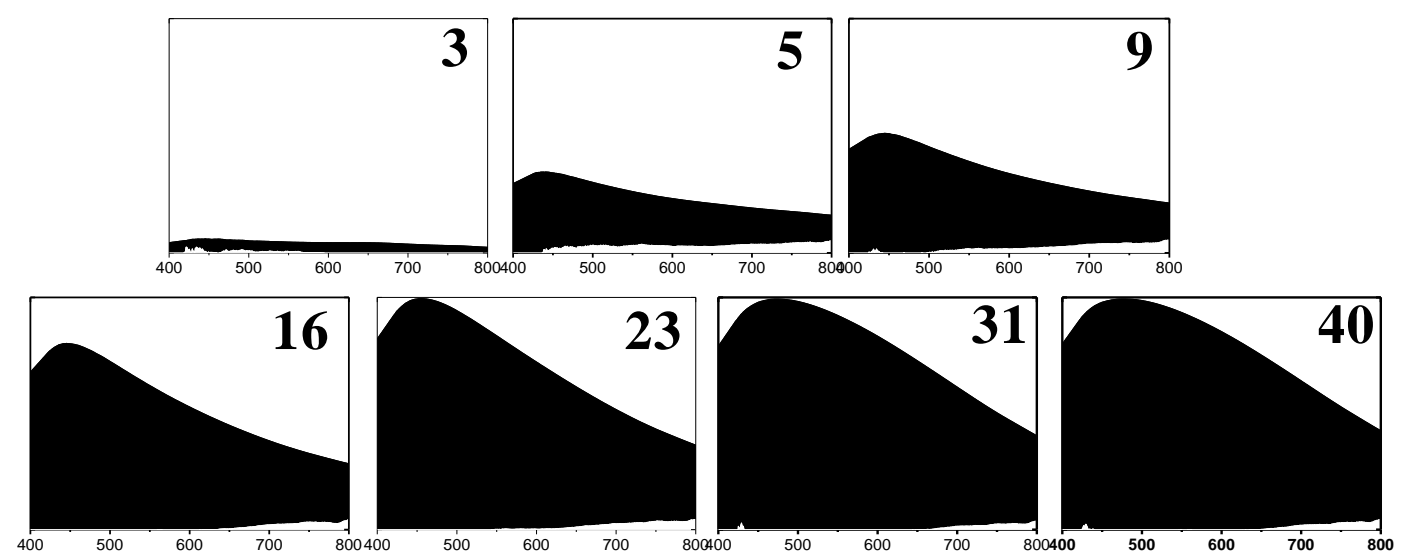

Figure $\mathrm{S} 9$ The absorption integral area of $\mathrm{PDA} @ \mathrm{SiO}_{2}$ structurally colored arrays with different thicknesses $(\mu \mathrm{m})$ in water. 


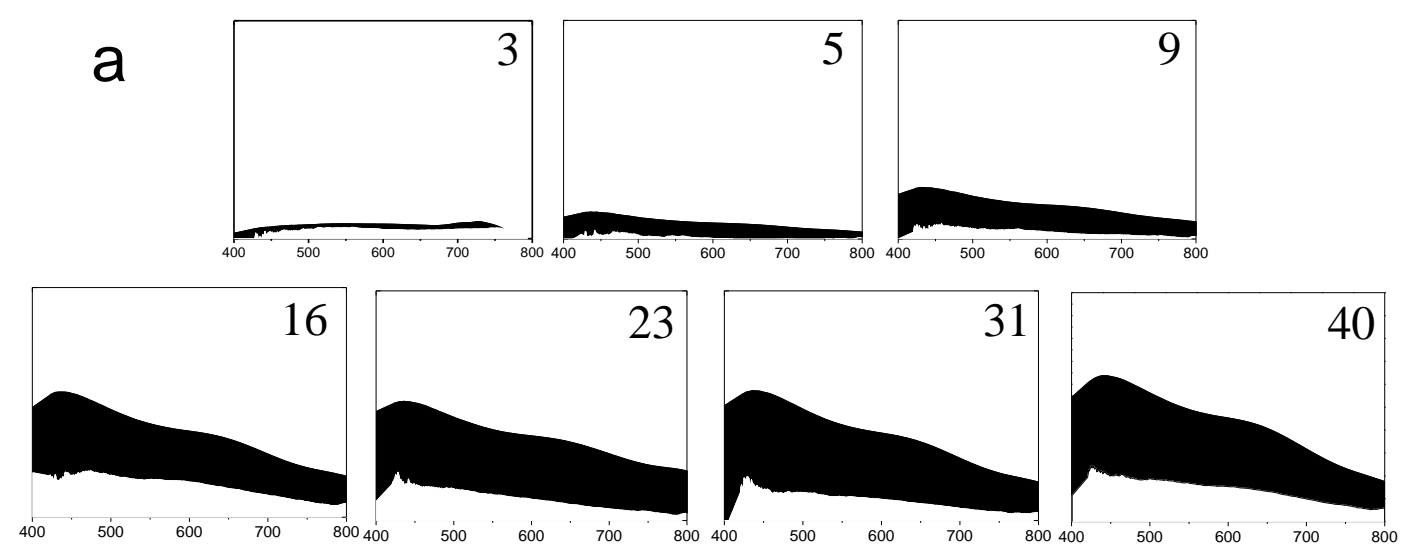

b

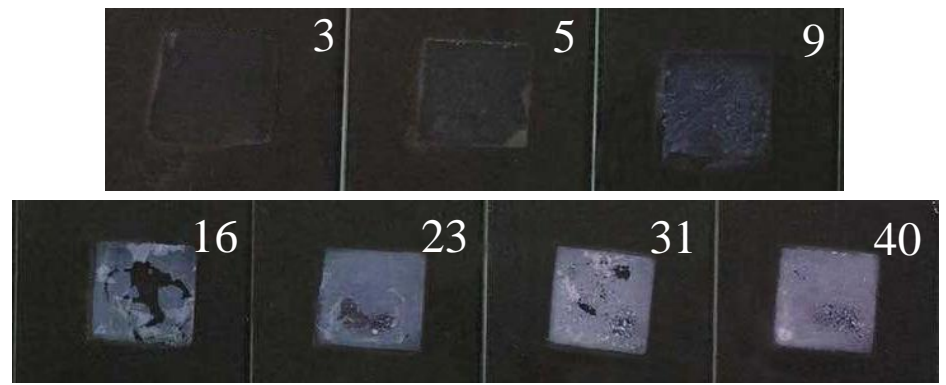

C

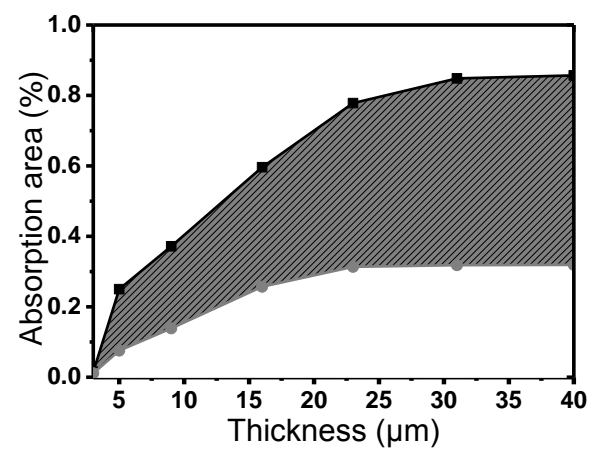

Figure $\mathrm{S} 10(\mathrm{a}, \mathrm{b})$ Photographs and absorption integral area of the $\mathrm{SiO}_{2}$ arrays with thicknesses of $3 \mu \mathrm{m}, 5 \mu \mathrm{m}, 9 \mu \mathrm{m}, 16 \mu \mathrm{m}, 23 \mu \mathrm{m}, 31 \mu \mathrm{m}, 40 \mu \mathrm{m}$ after water-wetting. (c) Comparison curves of the absorption integrated area of PDA@ $\mathrm{SiO}_{2}$ arrays (black line) and $\mathrm{SiO}_{2}$ arrays (grey line) of different thicknesses after immersion in water. 


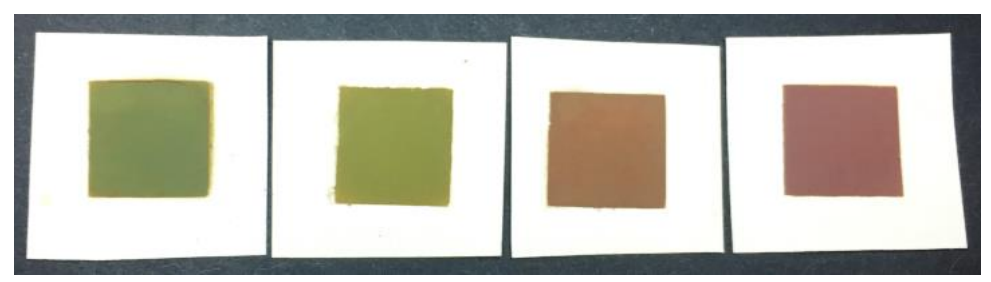

Figure S11 Photographs of the structurally colored PDA@ $\mathrm{SiO}_{2}$ arrays fabricated by diameters of $217 \mathrm{~nm}, 232 \mathrm{~nm}, 263 \mathrm{~nm}$ and $295 \mathrm{~nm}$ in white paper.

\section{$36 \pm 2^{\circ}$}

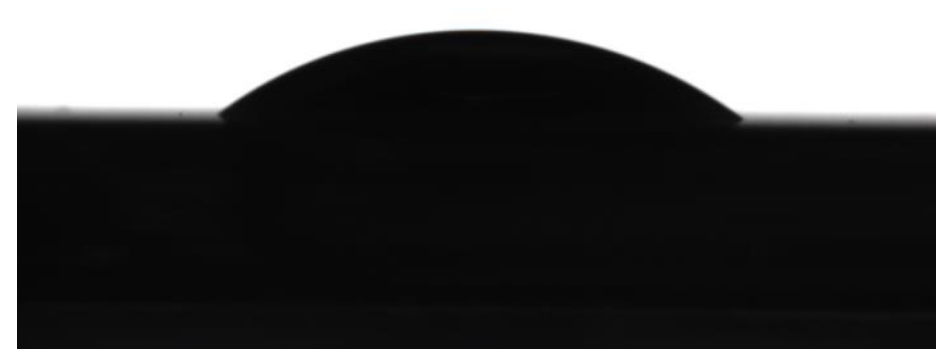

Figure S12 The contact angle of glass

Description of Movies

- Movie S1 shows the hidden pattern of PDA@ $\mathrm{SiO}_{2}$ amorphous arrays was revealed by water. 